\title{
The Morphology of Annealed Supported Palladium Films for Hydrogen Separations
}

\author{
Barbara Carstensen, B. Ceylan Akis, Bruce H. Ballinger, David C. Calabro, Harry W. Deckman, Ivy D. \\ Johnson, Randall D. Partridge \\ ExxonMobil Research \& Engineering Company, 1545 Route 22 East, Annandale, New Jersey 08801
}

Hydrogen is known to be highly soluble and easily transported in palladium. These characteristics make Pd suitable for selectively separating hydrogen from gaseous mixtures. Mechanistically, Pd separates $\mathrm{H}_{2}$ from mixtures by adsorbing $\mathrm{H}_{2}$ on the surface of a $\mathrm{Pd}$ membrane, dissociating it to 2 hydrogen atoms, which are then transported through the membrane. The hydrogen atoms are then recombined on the opposite side of the membrane to form $\mathrm{H}_{2}$. In the absence of non-selective defect pathways, $\mathrm{Pd}$ membranes are used to produce the highest purity hydrogen possible. There are many markets for the production of high purity $(99.9999 \%) \mathrm{H}_{2}$ via a solution-diffusion mechanism; among them are on-site hydrogen generation, semi-conductor fabrication and spent nuclear fuel and waste storage.

The focus of this work is to study the morphology of annealed sputter-coated supported Pd films. In order to recover high purity $\mathrm{H}_{2}$ the $\mathrm{Pd}$ membrane should be dense and defect free. These experiments will help to determine the best annealing conditions required to fabricate a dense, defect-free $\mathrm{Pd}$ membrane capable of yielding optimum $\mathrm{H}_{2}$ selectivity and flux.

One-inch alumina disks were sputter-coated with thin films of Pd then fractured into pie shaped pieces. Some pieces were annealed at pre-determined temperatures in a mixture of $\mathrm{H}_{2}$ and Ar for predetermined lengths of time. The unannealed sputter-coated films and each of the annealed films were examined by SEM to determine any change in the surface morphology due to annealing. The fractured edge of each film was also viewed by SEM to determine the internal structure of the films as well any structural defects.

The initial results of annealing the Pd films at moderate temperatures, for long periods of time produced films with a columnar structure. The columnar structure seen in Image 1 is undesirable due to the presence of grain boundaries running through the entire thickness of the film, which provides defect pathways. This structure would not be expected to yield high purity hydrogen. However, a dramatic change in the surface morphology of the Pd film occurred when the film was exposed to annealing for short times at high temperatures as shown in Images 2-5. Significant changes can be seen at both high and low magnification as the large grains of the Pd metal structure emerged after annealing. The x-sections of the same films show the 'as sputtered film' to have a mixed structure; a columnar structure is seen at the base of the film with a dense area in the middle and a porous area at the top shown in Image 6. The annealed counterpart, Image 7, was dense across the entire fractured edge of the film having no visible defects. This is the desired film structure for a $\mathrm{Pd}$ membrane for it to have applications in $\mathrm{H}_{2}$ separations.

References

[1] B. Ceylan Akis. "Preparation of Pd-Ag/PSS Composite Membranes for Hydrogen Separation." MS Thesis, Worcester Polytechnic Institute, May 2004.

[2] F. Roa et. al., Ind. Eng. Chem Res. 2003, 42, 5827-5835 


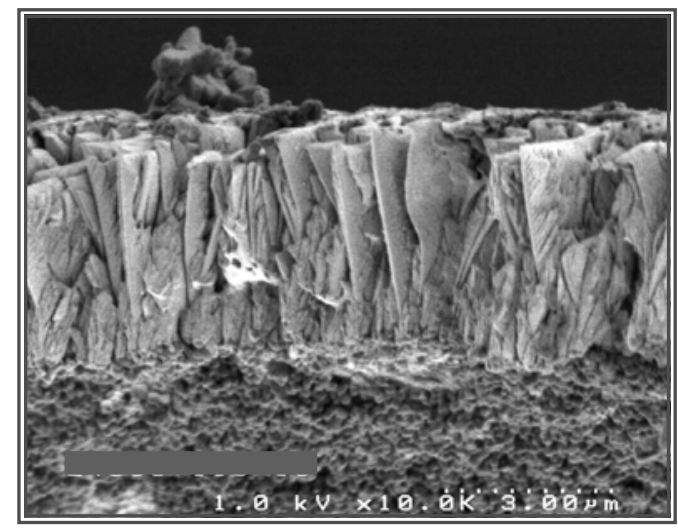

\section{Image 1}

Columnar Structure from

Annealing at Moderate

Temperature for Long Times
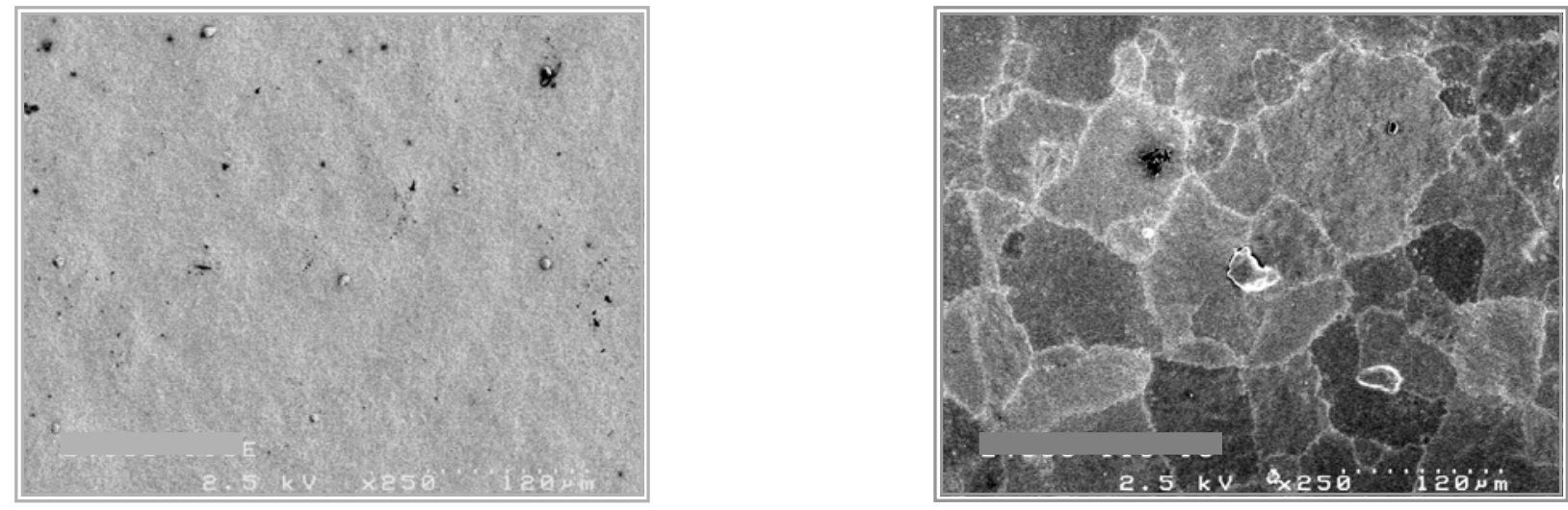

Image 2, Unannealed
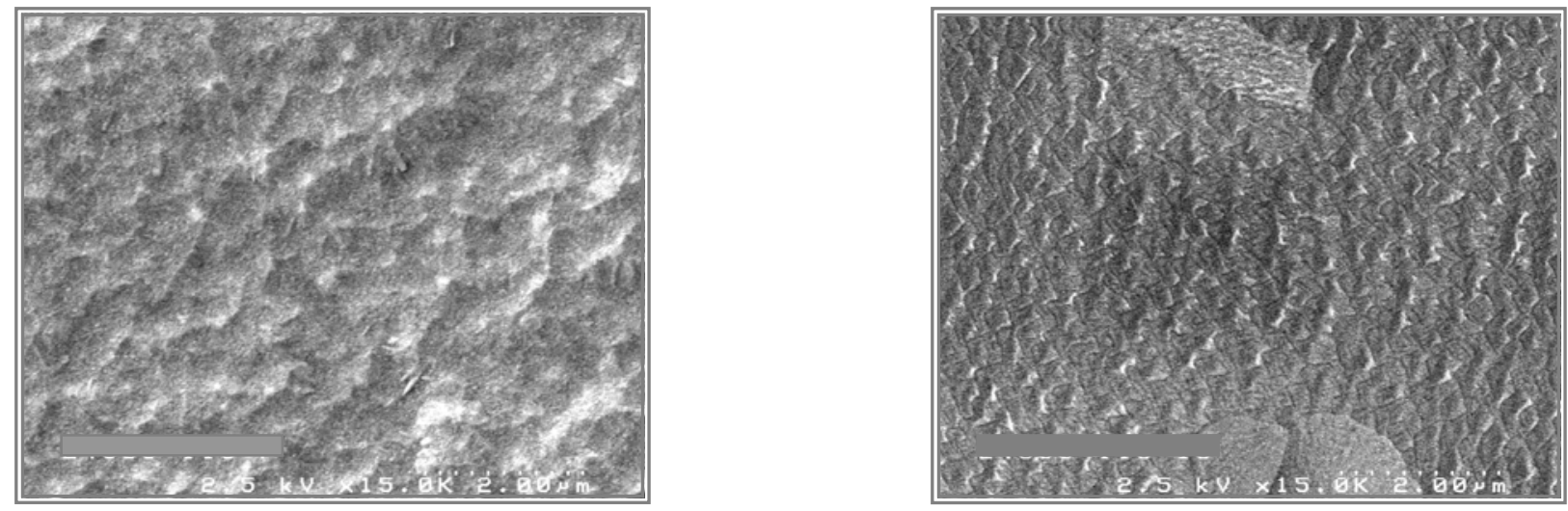

Image 4, Unannealed
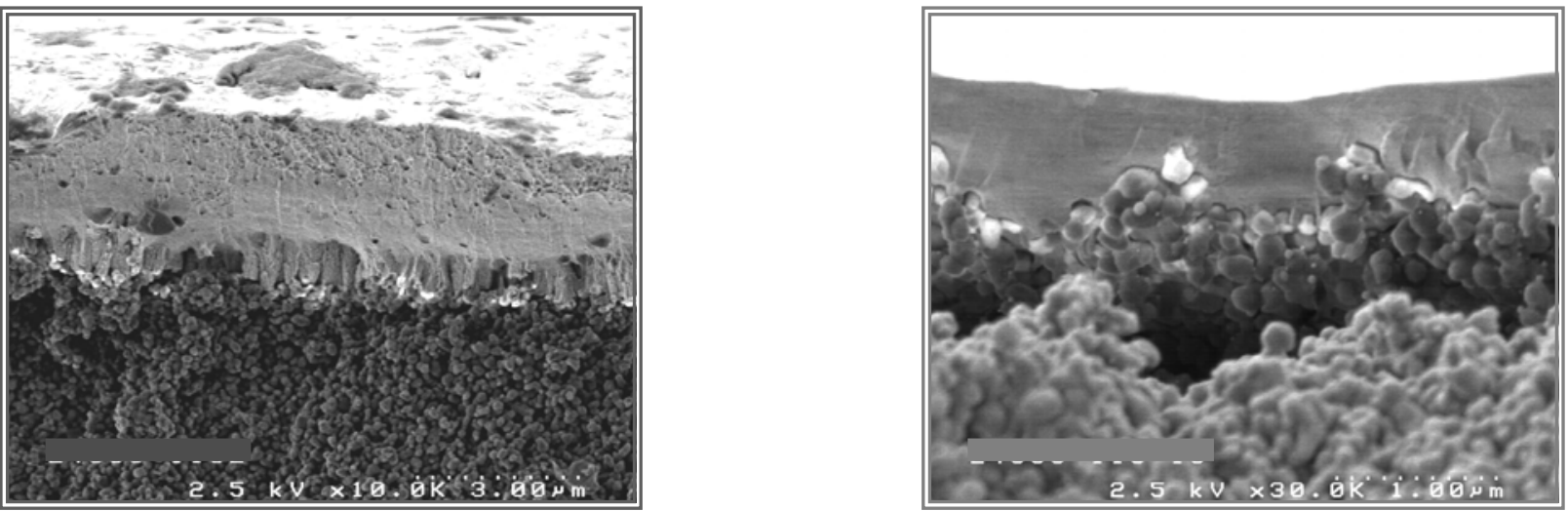